\title{
An Electronic Health Record-Integrated Computerized Intravenous Insulin Infusion Protocol: Clinical Outcomes and in Silico Adjustment (Diabetes Metab J 2020;44:56-66)
}

\author{
Dongwon Yi \\ Division of Endocrinology and Metabolism, Department of Internal Medicine, Pusan National University Yangsan Hospital, Pusan National University School \\ of Medicine, Yangsan, Korea
}

Blood glucose control in hospitalized patients is essential because both hyperglycemia and hypoglycemia are associated with adverse outcomes, such as increased risk of infection, delays in surgical procedures or discharge from the hospital, and increased mortality [1-5]. Therefore, consensus statements about glycemic control in inpatients from several medical organizations, such as the American Diabetes Association, American Association of Clinical Endocrinologists, American College of Physicians, and Society of Critical Care Medicine, generally target glucose levels between 140 and $180 \mathrm{mg} / \mathrm{dL}$ $[2,3,5]$.

In this article entitled, "An electronic health record-integrated computerized intravenous insulin infusion protocol: clinical outcomes and in silico adjustment," Park et al. [6] aimed to investigate the clinical outcome of a computerized intravenous insulin infusion (CII) protocol integrated to the electronic health record (EHR) system and to adjust the CII protocol in silico using the EHR-based predictors of the outcome. They showed that EHR-integrated CII protocol successfully maintained target glucose level while minimizing the risk of hypoglycemia. After EHR-based adjustment, the CII protocol reduced the delayed responses in silico patients without increasing hypoglycemia incidence. However, there are still some issues not covered in this study.
First, the reasons for selection of the Yale insulin infusion protocol should be mentioned in this study. There are a number of published insulin infusion protocols. However, the single most effective and safe insulin infusion protocol for controlling blood sugar in hospitalized patients has not been identified [7]. The Yale insulin infusion protocol was developed for the management of critically ill hyperglycemic patients in the medical intensive care unit, not specifically adjusted for those patients with diabetic emergencies, such as diabetic ketoacidosis or hyperglycemic hyperosmolar states or noncritical illness $[1,4]$. However, the reason why this protocol was applied to a very heterogeneous inpatient care settings, including perioperative glycemic control, continuous enteral feeding, diabetic ketoacidosis, and fasting for other reasons, was not discussed in the present study. Second, there is a discrepancy in target glucose levels in the study. The initial target glucose levels of the CII protocol is between 140 and $180 \mathrm{mg} / \mathrm{dL}$. However, the authors used a different target glucose levels between 70 and 180 $\mathrm{mg} / \mathrm{dL}$ in silico simulation. It is reasonable to apply the same target glucose levels throughout the study to reach a consistent and definite conclusion. The readers might be confused with inconsistent target glucose levels, which requires explanations for changes of the target value. Finally, discontinuation of the intravenous insulin infusion often leads to recurrence of hy-
Corresponding author: Dongwon Yi (D) https://orcid.org/0000-0003-3574-036X Division of Endocrinology and Metabolism, Department of Internal Medicine, Pusan National University Yangsan Hospital, Pusan National University School of Medicine, 20 Geumo-ro, Mulgeum-eup, Yangsan 50612, Korea

E-mail: drwonny@gmail.com
This is an Open Access article distributed under the terms of the Creative Commons Attribution Non-Commercial License (https://creativecommons.org/licenses/by-nc/4.0/) which permits unrestricted non-commercial use, distribution, and reproduction in any medium, provided the original work is properly cited. 
perglycemia. Therefore, a description of post-CII management to minimize this repulsive effects, such as subcutaneous insulin protocols, would improve the level of perfection of the study $[1,4,5,7,8]$.

Nevertheless, the present study is very provocative and interesting. Further head-to-head comparisons of the different CII protocols in the large-scale randomized trials including in silico simulation will be required for development of the best-tailored CII protocol for generalized use.

\section{CONFLICTS OF INTEREST}

No potential conflict of interest relevant to this article was reported.

\section{REFERENCES}

1. Goldberg PA, Siegel MD, Sherwin RS, Halickman JI, Lee M, Bailey VA, Lee SL, Dziura JD, Inzucchi SE. Implementation of a safe and effective insulin infusion protocol in a medical intensive care unit. Diabetes Care 2004;27:461-7.

2. Moghissi ES, Korytkowski MT, DiNardo M, Einhorn D, Hellman R, Hirsch IB, Inzucchi SE, Ismail-Beigi F, Kirkman MS, Umpierrez GE; American Association of Clinical Endocrinologists; American Diabetes Association. American Association of Clinical Endocrinologists and American Diabetes Associa- tion consensus statement on inpatient glycemic control. Endocr Pract 2009;15:353-69.

3. Jacobi J, Bircher N, Krinsley J, Agus M, Braithwaite SS, Deutschman C, Freire AX, Geehan D, Kohl B, Nasraway SA, Rigby M, Sands K, Schallom L, Taylor B, Umpierrez G, Mazuski J, Schunemann H. Guidelines for the use of an insulin infusion for the management of hyperglycemia in critically ill patients. Crit Care Med 2012;40:3251-76.

4. Marvin MR, Inzucchi SE, Besterman BJ. Computerization of the Yale insulin infusion protocol and potential insights into causes of hypoglycemia with intravenous insulin. Diabetes Technol Ther 2013;15:246-52.

5. Qaseem A, Chou R, Humphrey LL, Shekelle P; Clinical Guidelines Committee of the American College of Physicians. Inpatient glycemic control: best practice advice from the Clinical Guidelines Committee of the American College of Physicians. Am J Med Qual 2014;29:95-8.

6. Park SW, Lee S, Cha WC, Hur KY, Kim JH, Lee MK, Park SM, Jin SM. An electronic health record-integrated computerized intravenous insulin infusion protocol: clinical outcomes and in silico adjustment. Diabetes Metab J 2020;44:56-66.

7. Kelly JL. Continuous insulin infusion: when, where, and how? Diabetes Spectr 2014;27:218-23.

8. Kodner C, Anderson L, Pohlgeers K. Glucose management in hospitalized patients. Am Fam Physician 2017;96:648-54. 